\title{
SKAM - ophavsretlige grænser på det grænseløse Internet?
}

\begin{abstract}
This article examines some of the copyright-related questions that arise in the context of cross-border access to the Norwegian series SKAM. The programme has turned into a cultural phenomenon throughout the Nordics and rightholders' geo-blocking of consumers from other countries led to much awareness of cross-border access in January 2017, not least from the former Danish minister of culture. The EU-legislator has in the recent years proposed a variety of solutions to secure cross-border access to copyright-protected works. This article provides an overview on these initiatives and their complex interplay. A consumer-focused perspective is finding its way into the academic discourse and the lawmaker's agenda for copyright in the $21^{\text {st }}$ century. The article argues, however, that there is a long way until the traditionally unproblematic geographical delineation finds its balance on the Internet. Conventionally, an argumentation based on culture is used to justify a high level of protection for rightholders. In the light of transnational culture, this article reflects on transferring these considerations to crossborder access to content, i.e. the justification for a high level of access to transnational culture.
\end{abstract}

Keywords: Det digitale indre marked, ophavsret, geoblokering, grænseoverskridende portabilitet, multiterritoriale licenser

\section{Introduktion}

SKAM er et kulturfænomen. Ikke alene i dens oprindelsesland, men i hele Norden, især Danmark. I 2016 oplyste den norske public service-udbyder NRK, at hele 28 procent af SKAM-seerne af den tredje sæson kom fra Danmark. ${ }^{\text {ii }}$ SKAM er født på det 'grænseløse' internet og byder på et innovativt format, hvor små indslag i form af videoklip, Instagram-opslag eller skærmbilleder af SMS-tråde bliver lagt på nettet i blogformat. I januar 2017 var denne adgang dog pludselig ikke grænseløs længere: NRK måtte umiddelbart geoblokere adgang til serien, både via deres hjemmeside og NRK P3's egen SKAM-side, for udenlandske seere, efter at musikpladeselskabernes brancheforening IFPI påstod, at serien havde fået for mange udenlandske seere til at være dækket af musiklicensaftalen. .ii $^{\text {ii }}$

I Danmark blev denne udvikling mødt med meget opmærksomhed, og den netbaserede serie fik et (politisk) højdepunkt i debatten om grænseløs adgang i januar 2017, da tidligere kulturminister Bertel Haarder stillede et $\S 20$-spørgsmål til den nuværende kulturminister, om hun " $i$ det nordiske kulturministerråd [vil] arbejde for, at 
der igen bliver uhindret adgang til den norske tv-serie Skam for seere over hele Norden samt tilsvarende uhindret adgang til nabolands-tv generelt i hele Norden?"iv

Spørgsmålet om grænseoverskridende adgang til ophavsretsbeskyttede værker er imidlertid hverken en ny eller en nordisk problemstilling, men snarere en skærpet indre markeds-problematik, hvor eksklusive rettigheder og licenseringspraksis kolliderer med hensyn til det indre marked. I de seneste år har EU-lovgiver sat problematikken højt på dagsordenen og foreslået eller introduceret forskellige foranstaltninger med henblik på at mindske hindringer af grænseoverskridende adgang for EU-borgere. ${ }^{v}$ Det vil jeg belyse nærmere i det følgende.

\section{Når tjenester og borgere krydser grænser}

Lad os først kigge på de situationer, hvor onlinetjenester, som f.eks. NRK P3's SKAM, krydser grænser. Når vi ser på disse situationer af "grænseoverskridende" karakter, skal det bemærkes, at den juridiske terminologi afviger fra den metaforiske sprogbrug. Der bør i hovedtræk sondres mellem to scenarier: Det første scenarie finder sit anknytningspunkt i forbrugerens bevægelse over grænsen. En borger fra medlemsstat $A$ befinder sig $i$ medlemsstat B og ønsker at tilgå tjenester fra sit hjemland A. Dette vil eksempelvis være tilfældet, når en norsk forbruger tager til Danmark og forsøger at tilgå sine norske tjenester derfra. Det andet scenarie finder sit anknytningspunkt i selve onlinetjenestens bevægelsen over grænsen. En tjeneste fra medlemsstat A skal kunne tilgås af en forbruger i medlemsstat B. Dette vil være tilfældet, når en dansk forbruger prøver at tilgå en norsk onlinetjeneste fra sit hjemland. Det er således netop det sidstnævnte, som er tilfældet i den ovenfor beskrevne situation, hvor SKAM ikke kunne tilgås i Danmark.

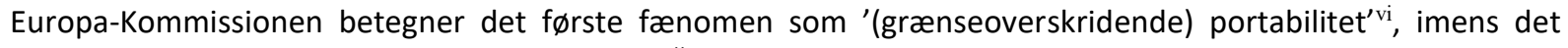
andet fænomen betegnes som 'geoblokering'. vii Disse to fænomener danner grundlag for sondringen i denne artikel. Det bør nævnes, at geoblokering beskriver den praksis at begrænse adgangen til indhold afhængig af brugerens geografiske placering ved hjælp af tekniske foranstaltninger. ${ }^{\text {viii }}$

\section{Den ophavsretlige dimension}

Der er en lang række ophavsretlige spørgsmål, som er interessante at belyse ved at bruge SKAM som unders $\varnothing$ gelsesgenstand. Denne artikel har til formål at granske de retlige spørgsmål, som opstår i forbindelse med udøvelsen af ophavsretten, navnlig i grænseoverskridende situationer. Ikke desto mindre er det behjælpeligt hurtigt at minde om nogle af ophavsrettens mest centrale aspekter.

Den ophavsretlige beskyttelse kan forstås således, at den har til formål at skabe incitamenter for ophavsmænd til at frembringe værker. Beslægtede rettigheder finder deres begrundelse $\mathrm{i}$ beskyttelsen af investering $\mathrm{i}$ skabelsen af værkerne. Forskellige aspekter af SKAM kan være ophavsretsbeskyttet. I modsætning til nogle andre immaterielle rettigheder, stiftes ophavsretten ikke gennem registrering, men opstår med skabelsen af selve værket. Det vil sige, at tekst, billeder eller videomateriale i form af SMS-tråde, Instagram-billede eller videoklip kan være ophavsretsbeskyttet, hvis disse opfylder værkshøjdekriteriet. ${ }^{i x}$ En vigtig begrænsning ligger i, at ophavsretten ikke beskytter idéer. ${ }^{\mathrm{x}}$ Også i situationer, hvor brugere selv kollaborativt bygger videre på serien, eksempelvis ved at lave 'memes' eller merchandise, opstår en række ophavsretlige spørgsmål.

Derudover spiller især brug af musik central rolle i SKAM (den officielle spilleliste på Spotify har 120.000 følgere). Hvor indhold, der er beskyttet af ophavsret og beslægtede rettigheder, bliver brugt, kræves udstedelse af licensrettigheder fra de forskellige rettighedshavere. Musikværker har oftest flere rettighedshavere (en eller flere musikautorer, tekstforfattere, udøvere, producenter/musiklabels mfl.), således at flere ophavsmænd kan have rettigheder til det samme værk. Ved licensering af musikværker er denne fragmentering af rettigheder, rettighedshavere og repertoire forbundet med høje transaktionsomkostninger (Schwemer 2015, 700).

Ophavsrettigheder bliver traditionelt forvaltet nationalt og licenseret for geografiske områder, der oftest svarer til landegrænser. Dette er imidlertid ikke en følge af lovgivningen, men snarere af den licenseringspraksis og de underliggende forretningsmodeller, som rettighedshavere har udviklet over en lang række år, og som er bygget på eksklusive territoriale rettigheder. Hvis man tager udgangspunkt i aftalefriheden og den eksklusive karakter 
af de pågældende rettigheder, bliver det tydeligt, at spørgsmålet om hvorvidt onlineindhold skal være tilgængeligt over grænser i vidt omfang er et retspolitisk spørgsmål. Men er det overhovedet noget, lovgiveren skal gribe ind i?

\section{EU's intervention på grænseoverskridende indhold}

Etableringen af det europæiske indre marked har været en af de primære politiske og legislative prioriteter i det europæiske samarbejde og kulminerede i traktaten om Den Europæiske Union i 1992. I takt med den stærkt voksende digitale sektor er etableringen af det 'digitale indre marked' ligeledes kommet på EuropaKommissionens dagsorden. Formålet er at afskaffe hindringer, når borgere og virksomheder handler på tværs af grænser. ${ }^{x i}$ Det vil ikke sige, at den europæiske lovgiver ikke tidligere har haft grænseoverskridende adgang til indhold på agendaen. Faktisk blev beslægtede spørgsmål allerede adresseret i sekundær lovgivning i 1989 i det såkaldte 'fjernsyn uden grænser'-direktiviii, som etablerede at medlemslande skal sikre modtagefrihed og ikke må hindre retransmission på deres område af fjernsynsudsendelser fra andre medlemsstater.

Ganske interessant er den EU-retlige dimension også, da der ved SKAM er tale om indhold fra Norge, som ikke er en del af EU men Det Europæiske Økonomiske Samarbejdsområde (EØS). Igennem EØS-aftalen har EFTAlandene Island, Liechtenstein og Norge siden 1994 fået adgang til EU's indre marked og er samtidig forpligtet til at behandle og implementere alle EU retsakter, som ændrer det indre marked og har E $\varnothing$ S-relevans. ${ }^{\text {xiii }}$

Tiltag på licenseringssiden: grænseoverskridende musik-licensering

En måde at adressere grænseoverskridende adgang på er at forenkle licensering af de relevante rettigheder. For at sikre grænseoverskridende, det vil sige multiterritoriale, licenser på musikområdet, har EU-lovgivning i 2014 delvis reguleret området ved direktiv 2014/26/EU om kollektiv forvaltning af ophavsret og beslægtede rettigheder samt multiterritoriale licenser for rettigheder til musikværker med henblik på onlineanvendelse i det indre marked. ${ }^{\text {xiv }}$ Direktivet blev i Danmark implementeret ved den omfattende lov om kollektiv forvaltning af ophavsret (LOV nr 321 af 05/04/2016) og ændringer i ophavsretsloven, men direktivet er på dette tidspunkt endnu ikke blevet en del af E $\varnothing \mathrm{S}$-aftalen som først forventes gennemført i $\emptyset$ bet af 2017. ${ }^{\mathrm{xv}}$

Direktivet introducerer bl.a. et system til udstedelse af multiterritoriale licenser for onlinemusikrettigheder, som skal sikre en licenspolitik for erhvervsbrugere, "der er tilpasset det grænseløse onlinemiljø, og som dækker flere territoriale områder" (jf. betragtning 39 i direktiv 2014/26/EU). ${ }^{\text {xi }}$ Direktivet er dog begrænset til kun at finde anvendelse på kollektiv forvaltning. Det vil sige, at musikrettigheder, som ikke bliver forvaltet af kollektive forvaltningsorganisationer, falder uden for direktivet.

Tiltag på licenseringssiden: oprindelseslandsprincip for tilknyttede onlinetjenester

I september 2016 offentliggjorde Europa-Kommissionen omfattende lovgivningsinitiativer med det formål at modernisere den europæiske ophavsret, herunder et forslag til en forordning om regler for udøvelse af ophavsretten og beslægtede rettigheder, der gælder for visse af radio- og tv-selskabernes onlinetransmissioner samt retransmissioner af radio-og tv-programmer (COM(2016) 594 final). Formålet med forordningen er at $\emptyset \mathrm{ge}$ den grænseoverskridende tilgængelighed af radio- og tv-selskabernes programmer for EU-borgere ved at forenkle den "kompleks[e] clearing af rettigheder med en lang række rettighedsindehavere" og dermed mindske transaktionsomkostninger. ${ }^{\text {vii }}$

Af afgørende betydning er indførelsen af oprindelseslandsprincippet i artikel 2 i udkastet, som imidlertid er begrænset til radio- og tv-selskabernes onlinetjenester, der er 'tilknyttet' de oprindelige udsendelser i form af

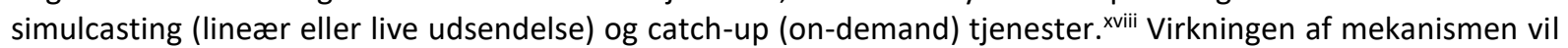
være, at radio- og tv-selskaber kun skal cleare de for den tilknyttede onlinetjeneste nødvendige rettigheder i den medlemsstat, hvor selskabet har sin hovedforretning (jf. artikel 2, stk. 1). ${ }^{\text {xix }}$

Selvom der er tale om en "mulighedsskabende" mekanisme, det vil sige ingen forpligtelse (jf. betragtning 11) og fortsat mulighed for aftalebaseret begrænsning af distributionen til specifikke territorier, blev forslaget mødt med skepsis blandt danske brancheorganisationer, rettighedshavere og forvaltningsorganisationer. Disse 
bekymringer bliver imødekommet i forordningen bl.a. i artikel 2, stk. 2, ved, at parterne skal tage "hensyn til samtlige aspekter af den tilknyttede onlinetjeneste, såsom den tilknyttede onlinetjenestes egenskaber og publikum samt sprogversionen" (jf. også betragtning 11). ${ }^{x x}$ Dermed skal princippet ikke begrænse rettighedshavernes mulighed "for fortsat at licensere rettigheder på territorial basis, som omfattet af kravene i EU-lovgivningen".

Frygten for svækkelsen af territorialt baserede forretningsmodeller afspejles også i Regeringens holdning i Kulturministeriets grund- og nærhedsnotat, hvori vigtigheden i "at en løsning på området tager hensyn til de særlige forhold, der gælder for tv- og filmbranchen, og at aftalelicenssystemet kan opretholdes" understreges. ${ }^{x i i}$ Ligeledes gav Folketingets Kulturudvalg i april 2017 udtryk for bekymring over lovvalgsreglen, bl.a. da dette vil gøre det mere "vanskeligt for danske rettighedshavere at aftale rimlige vederlag for brug af deres rettigheder". xxiii

Skulle forordningen blive vedtaget i den foreslåede form, vil det betyde en forenkling af licensering på visse områder. Det fremstår dog uklart, hvorvidt udsendelser, som primært foregår på onlinetjenester, vil være omfattet af forordningen, hvor den traditionelle tv-udsendelse er tilknyttet onlinetjenesten og ikke omvendt. Der pågår forhandlinger i Bruxelles herom.

Tiltag på adgangssiden: grænseoverskridende portabilitet

Indtil for nyligt fandtes der ikke nogle regler om tvungen grænseoverskridende portabilitet i primær eller sekundær EU-ret. I december 2015 præsenterede Europa-Kommissionen sit forslag til en forordning om sikring af grænseoverskridende mobile onlineindholdstjenester $i$ det indre marked ('portabilitetsforordning').xxiv Forordningens retsgrundlag er artikel 114 TEUF, som giver EU beføjelsen til at vedtage foranstaltninger, der vedrører det indre markeds funktion. Formålet er at indføre en fælles strategi for at sikre, at abonnenter på onlineindholdstjenester, der lovligt udbydes i deres bopælsmedlemsstat, kan få adgang til og bruge disse tjenester, når de midlertidigt opholder sig i en anden medlemsstat (artikel 1 i forordning (EU) 2017/1128).

Kernen af forordningen består af en juridisk fiktion indeholdt i artikel 4, som bestemmer, at de relevante ophavsretlige handlinger ved adgangen til og brugen af onlineindholdstjenester anses for udelukkende at finde sted i bopælsmedlemsstaten. Mekanismens effekt efterligner dermed oprindelseslandsprincippet fra servicedirektivet (2006/123/EF) og satellit- og kabeldirektivet (93/83/E $\varnothing \mathrm{F})$. Med andre ord udgør portabilitetsforordningen et de facto indgreb i aftalefriheden via en juridisk fiktion med bagvedliggende hensyn til det indre marked og ultimativ forbrugerbeskyttelse.

Forordningens anvendelsesområde er begrænset på en række punkter: Pligten til at sikre grænseoverskridende portabilitet er rettet mod situationen, hvor et abonnement til en onlineindholdstjeneste leveres mod betaling (jf. artikel 3, stk. 1) og abonnentens bopælsmedlemsland kan identificeres. Gratis abonnementstjenester, på den anden side, kan - men er ikke forpligtet til at - tilbyde grænseoverskridende portabilitet "forudsat at abonnentens bopælsmedlemsland verificeres af udbyderen". ${ }^{x v}$ Hvorvidt public service-tjenester skal være omfattet af forordningen, blev drøftet af forskellige udvalg i Europa-Parlamentet. Disse tjenester vil ligeledes kunne gøre det muligt for deres abonnenter at drage fordel af forordningen under de nævnte betingelser som gælder for gratis abonnementstjenester. ${ }^{x \times v i}$

I februar 2017 nåede Europa-Parlamentet til enighed om forslaget, og forordningen (EU) 2017/118 vil finde

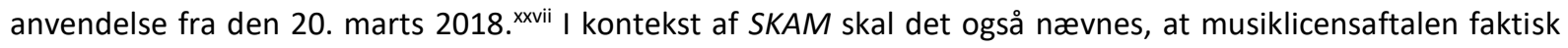
omfattede udbredelsen af indholdet til nordmænd i udlandet, det vil sige grænseoverskridende portabilitet. Problematikken lå snarere i spørgsmålet om, hvorvidt aftalen også dækkede den uventede høje efterspørgsel fra udlandet.

\section{Tiltag på adgangssiden: geoblokering}

Det leder mig til det sidste aspekt: adgangsbegrænsninger af indhold for brugere fra andre lande ved hjælp af tekniske foranstaltninger, det vil sige geoblokering. Denne praksis kan typisk føres tilbage til, at rettighedshavere 
af økonomiske årsager indgår aftaler med tjenesteydere for geografisk begrænsede områder (Riis \& Schovsbo 2016, s. 666).

I maj 2016 fremsatte Europa-Kommission udkast til en forordning om imødegåelse af geoblokering og andre former for forskelsbehandling på grundlag af kundernes nationalitet, bopæl eller hjemsted i det indre marked og om ændring af forordning (EF) nr. 2006/2004 og direktiv 2009/22/EF (COM(2016) 289 final). Formålet med forordningen er at afskaffe 'ubegrundet' geoblokering og "at give kunderne bedre adgang til varer og tjenesteydelser på det indre marked ved at forhindre, at erhvervsaktørerne praktiserer både direkte eller indirekte forskelsbehandling gennem en kunstig opsplitning af markedet på grundlag af kundernes bopæl." ${ }^{\text {“xviii }}$

Ifølge artikel 4, stk. 1, lit. b, gælder forbud mod forskellige generelle betingelser for adgang til deres tjenesteydelser afhængigt af kundernes nationalitet, bopæl eller hjemsted, dog ikke for ydelser "hvis vigtigste funktion er at give adgang til og mulighed for brug af ophavsretligt beskyttede værker eller andre beskyttede frembringelser". Med andre ord ville adgang til ophavsretsbeskyttet indhold i første omgang ikke være omfattet af forordningen. Efter Europa-Parlamentets ændringsforslag, er Europa-Kommissionen nu ved at overveje at udvide til ophavsret beskyttede værker alligevel. ${ }^{\text {xix }}$ Spørgsmålet er også her, hvorvidt dette overhovedet vil finde anvendelse på public service-tjenester.

\section{Vejen frem: Hvordan skal grænseoverskridende adgang sikres?}

Bertel Haarder har trukket sit § 20-spørgsmål tilbage, NRK har fået en ny musiklicensaftale på plads, og SKAM forlænges ikke efter den fjerde sæson. Happy end?

\section{De lege ferenda: usikkert og kompleks sammenspil}

Som belyst er EU-lovgiveren ved at adressere nogle af hindringerne i form af grænseoverskridende portabilitet og 'ubegrundet' geoblokering ved brug af indhold på nettet i en række instrumenter. Det er bemærkelsesværdigt, at den europæiske lovgiver satser på forordninger på nogle områder, det vil sige en totalharmonisering, efter tidligere at have stolet på 'soft law' (såsom anbefalinger) eller direktiver.

Derudover viser der sig med de forskellige horisontale instrumenter, navnligt forordninger og direktiver, et yderst komplekst sammenspil. Et yderligere aspekt, som ikke har været genstand for denne artikel, er grænsefladen til konkurrenceretten. Almindelig europæisk konkurrenceret er i stand til at adressere og løse begrænsninger på grænseoverskridende adgang i et vist omfang, og de territoriale begrænsninger giver ifølge Riis \& Schovsbo (2016) ikke i sig selv anledning til en omfattende modernisering af ophavsretlige regler. Ikke desto mindre spiller EU's konkurrencemyndighed en central rolle i multiterritorial licensering (Schwemer, 2016) og adgang (jf. pay-tv sagen).

Direktiv 2014/26/EU, som faciliterer multiterritorial licensering på musikområdet, er det eneste af disse instrumenter, som er trådt i kraft på nuværende tidspunkt. Selv når portabilitetsforordningen finder anvendelse fra marts 2018 og hvis de forskellige øvrige lovforslag bliver vedtaget, forbliver der en lang række åbne spørgsmål og ikke adresserede aspekter, som hvorvidt onlinetjenester eller serier som SKAM overhovedet vil være omfattet. Og mildest talt er nogle forslag kontroversielle blandt rettighedshavere, som fører forhandlingerne og deres resultater i den politiske snarere end i den juridiske arena.

Aftalefriheden er et bærende civilretligt princip, som i et vist omfang bliver begrænset i det indre marked. I en snævrere forstand vil kun geoblokeringsforordningen og direktiv 2014/26/EU begrænse aftalefriheden som sådan, mens de andre regulativer virker aftalebegrænsende. I lyset af den kraftige modstand fra rettighedshavere er det dog uklart i hvilket omfang de forslåede tiltag vil blive en realitet. Kompleksiteten forhøjes yderligere med tanke på, at tredjepartstjenester såsom platforme som Instagram og Facebook bliver brugt mere aktivt. Mens det er teknisk muligt for NRK at begrænse adgangsmuligheder til deres egen hjemmeside, vil brug af andre platforme være underlagt deres vilkår og ofte ikke teknisk muligt at geoblokere. 
Transnational kultur og forbrugerperspektivet

Hvis vi tænker tilbage på Bertel Haarders intervention, er det værd at stille spørgsmålet om, hvad det betyder for den retspolitiske debat, når en tidligere kulturminister kritiserer den manglende grænseoverskridende adgang til ophavsretsbeskyttet indhold på baggrund af kulturhensyn som "den gensidige nordiske sprogforståelse".

I Lissabontraktaten fastslog lovgiveren i artikel 3, stk. 3 TEU, at Unionen "respekterer medlemsstaternes rige kulturelle og sproglige mangfoldighed og sikrer, at den europæiske kulturarv beskyttes og udvikles." I den konventionelle forståelse bliver kulturargumentet primært anvendt for at begrunde et højt beskyttelsesniveau af rettighedshavere. Men hvad hvis man overfører disse overvejelser til grænseoverskridende adgang til indhold, det vil sige begrundelsen for et højt adgangsniveau til transnational kultur?

Haarder kommenterer i sin skriftlig begrundelse, at "Pippi Langstrømpe har i så henseende haft større betydning end samtlige sessioner i Nordisk Råd." Og når sportsbegivenheder kan være af så væsentlig samfundsmæssig interesse, at fjernsynsforetagenders eneret begrænses i udnyttelsen så "en betydelig del af befolkningen [ikke] forhindres $i$ at kunne følge dem via direkte eller tidsforskudt transmission på gratis fjernsyn “ ${ }^{\text {“xx }}$, burde et lignende rationale ikke kunne udvides til kultur- og underholdningsindhold?

Mens ophavsretten eller dens udøvelse traditionelt ikke har taget hensyn til forbrugere som sådan (Hugenholtz \& Helberger, 2007), virker det tilsyneladende som om, den europæiske lovgiver er ved at kalibrere interesseafvejningen for så vidt angår grænseoverskridende adgang til værker, navnlig i form af portabilitets- og geoblokeringsforordninger. Adgangsdimensionen (Geiger, 2015) og, i forlængelse af dette, forbrugerbeskyttelse er ved at finde sin vej ind i den akademiske diskurs og lovgiverens agenda for ophavsretten. Men der er stadigvæk lang vej før den traditionel uproblematiske geografiske opdeling finder sin ligevægt på internettet.

\section{Referencer}

Europa-Kommissionen (2012). Meddelelse om indhold på det digitale indre marked, COM(2012) 789 final, Bruxelles, den 18.12.2012

Europa-Kommissionen (2015). En strategi for et digitalt indre marked i EU, COM(2015) 192 final, Bruxelles, den 6.5.2015

Europa-Kommissionen (2015). Forslag til Europa-Parlamentets og Rådets forordning om sikring af grænseoverskridende mobile onlineindholdstjenester i det indre marked, COM(2015) 627 final, Bruxelles den 9.12.2015

Europa-Kommissionen (2016). Forslag til en forordning om imødegåelse af geoblokering og andre former for forskelsbehandling på grundlag af kundernes nationalitet, bopæl eller hjemsted $\mathrm{i}$ det indre marked og om ændring af forordning (EF) nr. 2006/2004 og direktiv 2009/22/EF, COM(2016) 289 final, Bruxelles den 22.5.2016

Europa-Kommissionen (2016). Forslag til en forordning om regler for udøvelse af ophavsretten og beslægtede rettigheder, der gælder for visse af radio- og tv-selskabernes onlinetrans-missioner samt retransmissioner af radio- og tv-programmer, COM(2016) 594 final, Bruxelles, den 14.9.2016

Folketingets Europaudvalg (2017). Politisk udtalelse om forslag til reform af ophavsretten, 25. april 2017

Geiger, C. (2015). Copyright as an Access Right, Securing Cultural Participation through the Protection of Creators' Interests, Max Planck Institute for Innovation and Competition Research Paper No. 15-07 2015 
Hugenholtz, B. (2015). Extending the SatCab Model to the Internet, Study commissioned by BEUC (Brussels, 2015)

Hugenholtz B. \& Helberger, N. (2007). No Place Like Home for Making a Copy: Private Copying in European Copyright Law and Consumer Law, Berkeley Technology Law Journal (22), 1061-1098.

doi.org/doi:10.15779/Z38296M

Kulturministeriet (2016). Grund- og nærhedsnotat til folketingets Europaudvalg, 21. december 2016

Riis T. \& Schovsbo J. (2016). Den grænseløse onlinebruger - geografisk opdeling af markedet for online- og streamingtjenester. In Liber Amicorum Jan Rosén (pp. 665-680). Visby: Eddy.se.

Schwemer, S. F. (2015). Kollektiv forvaltning i informationssamfundet og det nye regime under direktivet 2014/26/EU i Danmark. NIR, 697-705.

Schwemer, S. F. (2016). Emerging models for cross-border online licensing. In T. Riis (Ed.), User Generated Law, Re-Constructing Intellectual Property Law in a Knowledge Society (pp. 77-98). Cheltenham: Edward Elgar.

Schovsbo, J., Rosenmeier, M., Salung Petersen, C. (2015). Immaterialret, 4. udgave 2015. Copenhagen: Juristog $\emptyset$ konomforbundets Forlag.

Schønning, P. (2016). Ophavsretsloven med kommetarer, 6. udgave 2016. Copenhagen: Karnov Group.

i Tak til professor Thomas Riis og professor Jens Schovsbo for deres værdifulde kommentarer til artiklen

ii Politiken (2016, oktober 28). 28 procent af 'Skam'-seerne er fra Danmark [artikel]. Lokaliseret på

http://politiken.dk/kultur/filmogtv/article5647726.ece

iii NRK P3 (2017, januar 13). Nå kan du ikke lenger se «SKAM» fra utlandet [blog post]. Lokaliseret på http://p3.no/na-kandu-ikke-lenger-se-skam-fra-utlandet/

iv Ifølge Folketingets forretningsorden § 20, kan et folketingsmedlem få "oplyst en ministers holdning til eller opfattelse af et offentligt anliggende (...)" ved et spørgsmål til vedkommende minister. Se Folketinget (2017, januar 23). § 20-spørgsmål S 602 Om adgang til nabolands-tv i hele Norden. Lokaliseret på http://www.ft.dk/samling/20161/spoergsmaal/s602/index.htm

${ }^{v}$ Den tidligere Europa-Kommission gennemførte eksempelvis en omfattende høring i 2014, hvor det første spørgsmål gik ud på, hvorfor det ikke er muligt at tilgå mange onlinetjenester overalt i Europa. Høringen resulterede i flere end 9.500 svar vi Den danske version af lovforslaget oversætter "portability" som "sikring af grænseoverskridende mobile onlineindholdstjenester", jf. lovforslaget i deres engelske og danske oversættelser

vii Europa-Kommissionen definerer geoblokering som "en fremgangsmåde, der benyttes af onlinesælgere af forretningsmæssige grunde, og som medfører, at brugerne nægtes adgang til websteder i andre medlemsstater." se Europa-Kommissionen, En strategi for et digitalt indre marked i EU, COM(2015) 192 final, s. 6

viii Se Riis \& Schovsbo (2016), s. 673

ix Ved værkshøjde forstås "kravene til en litterær eller kunstnerisk frembringelse, for at frembringelsen kan anses som et værk i ophavsretslovens forstand", jf. Schønning (2016), § 1, 1.3.1, s. 120

${ }^{x}$ Se litteratur om beskyttelse af TV formater og programkoncepter og U $1999.1762 \varnothing$ (tv-format), jf. Schønning (2016), § 2, 1.5, s. 164, og Schovsbo et al. (2015), s. $113 \mathrm{ff}$ og U 2014/888 H (Netto-reklamefilm)

${ }^{x i}$ F.eks. Europa-Kommissionens Meddelelse om indhold på det digitale indre marked, hvor den præsenterede dens to parallelle fremgangsmåder bestående af "indsats[en] for at revidere og modernisere EU's lovgivningsmæssige rammer for ophavsret" og af facilitering af en struktureret industridialog om "praktiske erhvervsorienterede løsninger", jf. EuropaKommissionen, Meddelelse om indhold på det digitale indre marked, $\operatorname{COM(2012)~} 789$ final, s. 2-3

xii Rådets direktiv 89/552/E ØF af 3. oktober 1989 om samordning af visse love og administrative bestemmelser i medlemsstaterne vedrørende ud øvelse af tv-radiospredningsvirksomhed, som er forløber af direktivet om audiovisuelle medietjenester

xiii Store Norske Lexikon (2016, juli 8). EØS [artikel]. Lokaliseret på https://snl.no/EØS 
xiv Grænseoverskridende licensering af musikværker fra kollektive forvaltningsorganisationer har beskæftiget Europakommissionen både i dens egenskab som EU's konkurrencemyndighed og i dens egenskab som legislativ initiativtager for eksempel i CISAC-sagerne (2000-2013) og i en række tidligere sager. Se også Schwemer (2015)

${ }^{\mathrm{xv}}$ Med andre ord er direktivet derfor endnu ikke implementeret i national ret i Norge. Jf. Regjeringen (2017, januar 1). Oversikt over sentrale EU- og EØS-saker i forvaltningen - januar 2017. Lokaliseret på https://www.regjeringen.no/no/dokumenter/vedlegg_planer2017/id2536935/

xvi Disse regler for kollektive forvaltningsorganisationers multiterritoriale kollektive licensering er indeholdt i afsnit III af direktivet 2014/26/EU og fastslår blandt andet mindstekrav og betingelser, der skal fremme en frivillig sammenlægning af musikrepertoirer

xvii Europa-Kommissionen, Forslag til en forordning om regler for udøvelse af ophavsretten og beslægtede rettigheder, der gælder for visse af radio- og tv-selskabernes onlinetransmissioner samt retransmissioner af radio- og tv-programmer, $\operatorname{COM}(2016) 594$ final, s. 2

xviii Kommissionens forslag er bl.a. baseret på en evaluering af satellit- og kabeldirektivet (93/83/E $\varnothing F$ ), som indførte oprindelseslandsprincippet for satellittransmissioner. Udvidelsen af princippet har fundet forskellige fortalere i litteraturen, herunder Hugenholtz (2015). En anden mulighed, som Kommissionen overvejede, var at udvide oprindelseslandsprincippet til også at omfatte såkaldte webcasting-selskaber. Dette blev afvist af Kommissionen "navnlig på baggrund af den usikkerhed, der er forbundet med markedets fortsatte udvikling og det faktum, at visse tjenester stadig er i deres vorden", Europa-Kommissionen, $\operatorname{COM(2016)} 594$ final, s. 4-6

xix Mekanismen bliver anset for at "åbne nye muligheder for radio- og tv-selskaberne, så de kan udbyde deres onlinetjenester på tværs af grænserne, navnlig for så vidt angår indhold, som ikke er afhængigt af territorial eneret.", se Europa-Kommissionen, $\operatorname{COM(2016),~} 594$ final, s. 5

xx Jf. Europa-Kommissionen, $\operatorname{COM}(2016)$, 594, betragtning 11 og Kulturministeriet, grund- og nærhedsnotat til folketingets

Europaudvalg, 21. december 2016 (revideret), s. 3

xxi Europa-Kommissionen, $\operatorname{COM(2016),~} 594$ final, s. 5-6

xxii Kulturministeriet, Grund- og nærhedsnotat til folketingets Europaudvalg, 21. december 2016 (revideret), s. 13

xxiii Jf. Folketingets Europaudvalg, Politisk udtalelse om forslag til reform af ophavsretten, 25. april 2017, s. 2

${ }^{\text {xxiv }}$ Europa-Kommissionen, Forslag til Europa-Parlamentets og Rådets forordning om sikring af grænseoverskridende mobile onlineindholdstjenester i det indre marked, $\operatorname{COM}(2015) 627$ final

${ }_{\mathrm{xxv}}$ Europa-Parlamentets retsudvalg (JURI) foreslog b.la., at der indføres en ny artikel 3a om grænseoverskridende portabilitet af gratisabonnementtjenester, som fungerer som opt-in i en tidligere 'Draft Report'. Den endelige forordning adresserer disse tjenester i artikel 6 om grænseoverskridende portabilitet af onlineinholdstjenester, der stilles til rådighed uden betaling i penge

xxvi Ifølge betragtning 18 anses betaling af en obligatorisk gebyr for offentlige tv- og radioselskaber ikke som "betaling $\mathrm{i}$ penge" for en onlineindholdstjeneste

xxvii Det Europæiske Råd (2017, februar 2). Portabilitet af digitale indholdstjenester: Enighed mellem EU-formandskabet og Parlamentet [pressemeddelelse]. Lokaliseret på http://www.consilium.europa.eu/da/press/press-releases/2017/02/07portability-digital-content-services/

xxviii Europa-Kommissionen, $\operatorname{COM(2016)~} 289$ final, s. 2

xxix I Europa-Parlamentets industri, forskning og energi udvalg (ITRE) blev der bl.a. påpeget en udvidelse til tjenesteydelser, hvis vigtigste funktion er at give adgang til ophavsretsbeskyttede værker, forudsat udbyderen har de relevante rettigheder (jf. ændringsforslag 132 og 133 i Europa-Parlament, Industri, Forskning og Energi Udvalg, Amendments 42-164, Draft Opinion, 15.11.2016. Lokaliseret på http://www.europarl.europa.eu/sides/getDoc.do?type=COMPARL\&reference=PE594.031\&format=PDF\&language=EN\&secondRef=01

xxx Jf. § 1, stk. 2 bekendtgørelse $\mathrm{nr} 546$ af 19/04/2015 om udnyttelse af tv-rettigheder til begivenheder af væsentlig samfundsmæssig interesse 